\title{
Itinerario poético del cuerpo en vértigo: el personaje de Alejandra Pizarnik y el valor ontologizador de la despersonalización del yo poético
}

Palabras clave: Alejandra Pizarnik, corporeidad, despersonalización, valor ontologizador del lenguaje poético, experimento irrepetible

«Non costruisco se non distruggendo» Alberto Giacometti (en Juliet, 1986: 83).

\section{Introducción}

El objetivo del presente trabajo es estudiar la relación entre el cuerpo y la palabra en la obra de la poeta argentina, Alejandra Pizarnik, con especial atención al fenómeno de la despersonalización del yo poético. La principal línea de investigación parte del concepto del valor ontologizador del lenguaje poético, puesto que es precisamente la relación que el sujeto tiene con el lenguaje la que define las tensiones principales de la poética de Pizarnik. El trabajo obsesivo sobre el lenguaje vincula a la poeta al concepto de fatum, el destino poético del sujeto, que introduciremos en nuestro análisis a partir del libro titulado La escritura invisible: El discurso autobiográfico en Alejandra Pizarnik publicado por Patricia Venti (2008a). La autora utiliza este concepto en relación con la creación poética pizarnikiana para demostrar que la poeta determina su destino poético a través de la imposibilidad del lenguaje, lo que conduce al sujeto hacia su disolución y a la poeta al suicidio. En este artículo pretendemos usar la afirmación de Venti desde un punto de vista diferente, es decir, lejos del determinismo que pretende buscar las razones de la muerte del sujeto y 
de la poeta en la imposibilidad de la escritura, entender este destino como uno de los puntos que permite a la poeta escribir como si estuviera arriesgándolo todo. Se analizarán entonces las consecuencias y las posibilidades de tal destino poético con respecto al estudio del personaje pizarnikiano. Lo dicho supone un ejercicio mayor que el de la investigación cronológica de tal personaje, un análisis donde pretendemos buscar nuevos acercamientos al tema de la despersonalización. Con ello nos referimos sobre todo a dos posibilidades del estudio de la obra de Alejandra Pizarnik: primero, ofrecer una lectura donde su poética es entendida como un experimento irrepetible, es decir, leer su obra más allá de la expresión del intento fracasado de la poeta de unir el cuerpo y la palabra, la vida y la poesía, y segundo, analizar los poemas como si se tratara de una experiencia post mortem, donde el sujeto a través de la enajenación de la corporeidad escribe como si estuviera muerto para que el poema pueda establecerse como incesante llamamiento de lo ausente.

\section{La despersonalización del yo poético: sujeto, nombre, identidad y cuerpo}

El proceso de despersonalización, conocido también bajo otros nombres: fragmentación del yo poético, desdoblamiento y descorporización, es principalmente una herramienta utilizada para deshacer las estructuras de la lógica y del lenguaje convencionales. Estamos hablando de un proceso cuyo fin es la transformación del sujeto poético. En Notas sobre la poesía bispanoamericana actual Pedro Lastra (1985) relaciona tal transformación con la concepción del lenguaje. Constata que «La transformación del sujeto es inseparable de una transformación de su palabra», y define la despersonalización como «traspasos de la palabra, desdoblamientos que delatan un intento paradojal de despersonalización del hablante» (Lastra, 1985: 134). Viendo el proceso del desdoblamiento a la luz de la creación de los dobles, deberíamos dejar claro que el personaje literario de Alejandra Pizarnik es distinto de la creación de los dobles, tal y como podemos apreciar en el ejemplo de los heterónimos de Fernando Pessoa. En la obra de Pessoa la creación de los dobles va más allá de la pérdida de la identidad del yo poético, puesto que es precisamente debido a la fragmentación que la identidad llega a establecerse de un modo absoluto. Alejandra, voraz lectora de Pessoa, define la creación de los heterónimos como «una fertilidad secreta: el yo termina por ser corroído» (Pizarnik, 2002: 241). En el caso del personaje literario de Alejandra Pizarnik no se podrían repetir sus palabras acerca de los dobles de Pessoa, ya que el resultado del proceso del desdoblamiento - la creación de 
varias voces - hace que la pérdida de la identidad se profundice en el continuo acto del escribir. Lo que se multiplica en la obra de la poeta entonces no son los dobles, «[...] sino [...] una serie de flujos en constante devenir. En el pliegue las multiplicidades de Alejandra adquieren nombre y características marcadas, convirtiéndose en distintas líneas de fuga» (Daza, 2005). Paulina Daza describe las desarticulaciones del sujeto en la obra de Pizarnik como una suerte de fuga, perseguida a través de la pluralidad de la poesía, es decir, a través de las voces poéticas que emergen en el espacio textual. Cabe añadir, como veremos también a continuación, que el ejercicio poético y su proceso más representantivo, - la despersonalización, no se caracterizan solamente por ser fuga, sino también por ser búsqueda continua. Este tipo de dialéctica de contrarios (fuga / búsqueda) se puede observar también en las demás características de la obra de Pizarnik (en los emblemas poéticos, en el deseo de unir la vida y la poesía, etc.) y se caracteriza por las leyes rizomáticas, fragmentarias, que en el espacio textual buscan los puntos fijos para detenerse. Para analizar la trayectoria de estas «líneas de fuga» observaremos las consecuencias de la despersonalización a partir de la triple negación que tiene lugar en la obra de la poeta: la negación del lenguaje, la del cuerpo y la de la identidad de la autora como poeta (el personaje de Alejandra Pizarnik).

\section{El valor ontologizador del lenguaje: "la tenebrosa ambigüedad del lenguaje» ${ }^{1}$}

La principal relación entre la vida y la poesía, es decir, el cuerpo y la palabra, protagonizada por el cuestionamiento del valor ontologizador del lenguaje, es el origen de la tensión principal en la poética de Alejandra Pizarnik y es a la vez la razón del destino poético del personaje pizarnikiano. La poeta expresó su deseo de unir la poesía y la vida en numerosas ocasiones, siendo una de ellas el artículo sobre Artaud El verbo encarnado:

Aquella afirmación de Hölderlin, de que «la poesía es un juego peligroso», tiene su equivalente real en algunos sacrificios célebres: el sufrimiento de Baudelaire, el suicidio de Nerval, el precoz silencio de Rimbaud, la misteriosa y fugaz presencia de Lautréamont, la vida y la obra de Artaud ... // Estos poetas, y unos pocos más, tienen en común el haber anulado - o querido anular - la distancia que la sociedad obliga a establecer entre la poesía y la vida (Pizarnik, 2012: 269).

1 Pizarnik, 2013: 416. 
La propuesta de poner en juego la vida celebra la exaltación inicial del protagonismo del lenguaje, lo que implica también que éste se vuelve un espacio auténtico, privilegiado para la expresión artística. La cuestión del privilegio verbal que pronuncia el espacio del poema como el espacio de un conocimiento total, pone a la poeta y al poema en una relación de contrarios: por un lado asume la poesía como un juego peligroso y por otra parte la otorga toda la verdad epistemológica. Es más, lejos de su importancia como elemento constructor del poema se nos presenta el lenguaje en la poética de Alejandra Pizarnik como una experiencia mucho más real de lo que habitualmente entenderíamos bajo la experiencia cotidiana, que es, según la fuerza visionaria de la poeta, menos real que el mundo textual. Es por ello que Alejandra crea un personaje literario. En sus Diarios escribe: «La vida perdida para la literatura por culpa de la literatura. Quiero decir, por querer hacer de mí un personaje literario en la vida real fracaso en mi deseo de hacer literatura con mi vida real pues ésta no existe: es literatura» (Pizarnik, 2013: 405). Esta relación no señala a la «[...] vida-literatura como dos caras de una misma moneda» (Arruaga citado por Venti, 2008a: 161-162). Por tanto las instancias vida-poesía tampoco son intercambiables, lo que no quiere decir que no estén vinculadas. Para que haya literatura, tiene que existir un rechazo de lo que se entiende habitualmente bajo lo cotidiano, a partir del cual es posible la construcción de otra realidad, la poesía. Solamente a partir de este rechazo podemos hablar de un tipo de relación que se asemeja a «[...] un auténtico viaje a las tinieblas de la vida cotidiana, un verdadero descenso al abismo de las profundidades de la mente. Es, en definitiva, una lenta e inexorable preparación para la violencia y muerte» (Venti, 2008a: 81). Para aliviar el sujeto en disolución, la poeta trata de acudir a la palabra como a una especie del cobijo. En la entrevista que Martha Isabel Moia realiza con Pizarnik, la palabra aparece también como la única morada posible, amenazada por «el no saber nombrar lo que no existe. Es entonces cuando [dice Moia] te ocultás del lenguaje» (Moia en Pizarnik, 2013: 315). A lo que Pizarnik responde: «Con una ambigüedad que quiero aclarar: me oculto del lenguaje dentro del lenguaje. Cuando algo -incluso la nada - tiene un nombre, parece menos hostil» (Pizarnik, 2013:315). El hecho de ocultarse del lenguaje dentro del lenguaje es un acto de rebelión que encuentra su correspondencia en luchar contra el lenguaje con el lenguaje, lo que al final genera una red de fragmentos (con ello me refiero sobre todo a los últimos poemarios de Pizarnik, Extracción de la piedra de la locura y el Infierno musical, incluyendo los poemas no recogidos en los libros y publicados en el tomo de Poesía completa) donde la nueva realidad, creada y representada por el poema, no puede 
convertirse en un espacio total, anhelado por la poeta. Tal realidad incluso llega a ser «una extraña paradoja: la de un acto mudo; y como no hay más realidad en Pizarnik que la narración, el silencio del "secreto" se confunde enteramente con el blanco del relato: el sentido se detiene» (Venti, 2008b: 61). De este modo el lenguaje ya no tiene el poder de satisfacer el espacio del poema, puesto que se convirtió en aquella instancia que no se muestra sólo dudosa sino también fatal: «[...] También este / poema es posible que sea una trampa, un escenario más» (Pizarnik, 2013: 266). Entonces lo único que puede hacer la poeta es arriesgarse escribiendo, porque «Es en el poema, particularmente, donde el límite de lo posible es transgredido de buena ley, arriesgándose» (Pizarnik, 2012: 304). El riesgo supone asumir la insuficiencia del lenguaje, apoyándose sobre un gesto destructivo, subversivo a través del que Alejandra va arriesgándolo todo para hacer de la poesía una ceremonia del vivir, un reto a partir del cual la fragmentación y el silencio de las palabras emergen como nuevas posibilidades del acercamiento y de la búsqueda del centro del yo poético, para descubrir las verdades poéticas y para cuestionar la relación que este tiene con el lenguaje y con la creación artística. Este gesto destructivo consiste, según la cita de Alberto Giacometti que encabeza este artículo, en destruir para construir y comprende la poesía en su totalidad como un «lugar donde todo sucede» (Pizarnik, 2013: 299), lo que según el paradigma de lo absoluto significa un lugar, una realidad en la que se transgreden y aniquilan los límites de la lógica binaria de lo cotidiano y donde es posible sobre todo el hecho de sobrellevar la poesía misma, de entenderla como invocación y exorcismo.

\section{Las destrucciones del cuerpo: la ofrenda y el sacrificio}

Alejandra, en el poema titulado Destrucciones, escribe: «Del combate con las palabras ocúltame / y apaga el furor de mi cuerpo elemental» (Pizarnik, 2013: 159). La enajenación del sentimiento de la corporeidad une la ambigua relación de la poeta con el lenguaje, con la del cuerpo y con la de su propia identidad. Los cuerpos físico y poético se convierten en las herramientas de la ofrenda y del sacrificio. En los primeros poemarios la creencia en la palabra y su poder sanador todavía preserva su cuerpo textual como un material del sacrificio, como una posibilidad de que todo poema escrito puede llegar a ser una manera de ofrenda. Esta posibilidad se invierte cuando la relación que Alejandra tenía con su corporiedad empeora. El cuerpo, imposible de realizarse fuera de algo que no sea textual, emprende un camino hacia la errancia, puesto que «[...] se ha transformado en sólo un hilo conductor para llegar 
al gozo o la unión transformante» (Venti, 2008a: 216), a la unión que se entiende siempre como un conjuro dicho, expresado, pero lo que no garantiza también su realización. De ahí que el cuerpo puede ser entendido «[...] como un tránsito desde una condición inicial de sacrificio hasta la descorporización propiamente dicha» (Álvarez citado por Cancellieri, 2011: 227). La actitud sacrificial hacia el cuerpo, nombrada en los siguientes versos («Ojalá pudiera vivir solamente en éxtasis, haciendo el / cuerpo del poema con mi cuerpo, rescatando cada frase con mis días / y con mis semanas, infundiéndole al poema mi soplo a medida que / cada letra de cada palabra haya sido sacrificada en las ceremonias del vivir.» (Pizarnik, 2013: 269-270)) convierte el cuerpo en un terreno baldío, transitorio y el ejercicio artístico en una búsqueda incesante. Así, los procesos de la despersonalización y de la imposibilidad de unir el cuerpo y la palabra crean una imagen del poema como aquello que se produce tan solo en un éxtasis, en una situación que por ser extrema, es también la más real y sincera, o con otras palabras, la poeta empieza a escribir de tal manera que cada gesto condiciona el contenido verdadero del que escribe, desapareciendo. La noción de la corporeidad se puede explicar entonces del modo siguiente: el cuerpo no es la realización, sino la búsqueda que otorga el valor ontologizador a la poesía de Alejandra Pizarnik, de buscar sin encontrar, o con las palabras de Pizarnik, de «yacer porque alguien no viene» (Pizarnik, 2013: 344). El hecho de no estar en un lugar priva al cuerpo de su corporeidad y al sujeto de su papel constructor. En vez de ello estamos hablamos de un cuerpo negado y de un sujeto que padece el desdoblamiento constante, una serie de voces que se conjugan en el ejercicio irrepetible de ser otra vez la «niña que fuiste» (Pizarnik, 2013: 242), una imagen especular.

\section{La identidad perdida: «en el centro de la ausencia» ${ }^{2}$}

Si antes hablábamos de un cuerpo como «don para el sacrificio» (Cancellieri, 2011: 227) deberíamos añadir ahora también que el cuerpo tal y como se puede apreciar e interpretar en la obra de Pizarnik es un «cuerpo puro, asexuado y sin señas de identidad, lo cual nos remite al proceso de desdoblamiento y despersonalización trazado» (Cancellieri, 2011: 227). Tal cuerpo se convierte en un emblema de la extranjería, que es encabezado por el lenguaje, una instancia paralizada, y por el sujeto en disolución. Ellos orientan el cuerpo hacia los espacios textuales en donde éste podría abandonarse. Su relación con la materia verbal es una relación letal, que empieza en la poética de Pizarnik con

$2 \quad$ Pizarnik, 2013:381. 
el poema Sólo un nombre, porque sintetiza lo ajeno del nombre de la poeta por señalar distanciamento entre nombrar e identificar: «alejandra alejandra / debajo estoy yo / alejandra» (Pizarnik, 2013: 65). Con la triple manifestación del sujeto se repite el nombre que aparece en minúscula, que lo roba de su importancia y señala que la identidad ya no se puede igualar al nombre, el centro de la ausencia de todas las Alejandras (otros nombres o apodos de Alejandra) que se borraron para dar lugar a un personaje alejandrino. La iteración del nombre muestra la operación de autonominarse como un juramento a través del que se pretende llegar al espacio del deseo de la poeta y del sujeto. Pero este deseo se muestra imposible, tanto como el nombre que perdió su significado simbólico de antes, lo que señala ya el título del poema. La autonominación, también en la forma del pronombre de segunda persona, produce un efecto de extrañamiento y distancia. El proceso del sujeto de la enunciación que se evoca aquí es nombrarse, que es también el deseo de la poeta: nombrar significa existir. Por ello los efectos de la ilusión, de imitar la comunicación, de fingir la cercanía desembocan en una imagen especular: la de un nombre propio con minúscula, desvaluado y desposeído de su referencia. Cabe mencionar que es precisamente el proceso de la autonominación que inició la creación del personaje pizarnikiano. Éste surgió como respuesta a las multiplicidades o las distintas voces en su obra (los productos de la despersonalización) y se opone a los nombres de las Alejandras que la poeta fue cambiando durante su vida. Esos nombres son Buma, Flora, Blímele, Alejandra y Sasha (Piña, 1991: 19). Esto no quiere decir que las voces (la mayoría de las veces son representadas por los pronombres personales yo, tú, él, ella, etc.) y los nombres de las Alejandras no estén vinculados, - el enlace entre los nombres y las voces se forma precisamente mediante la disolución del yo poético y del fraccionamiento de la estructura de su identidad. El primer paso hacia la disolución, la enajenación y la extranjería es entonces «el gesto amputador que [...] reconvertirá [la poeta] en personaje desde la segunda de sus publicaciones: de Flora Alejandra Pizarnik a Alejandra Pizarnik» (Sala Calafell, 2013: 106).

El sentimiento de extranjería, protagonizado por la obsesión de la poeta con la literatura como la única verdad, finalmente traza su camino hacia la ausencia de todo lo que equivale a lo referencial. Dice Octavio Paz que la palabra es «[...] un puente mediante el cual el hombre trata de salvar la distancia que lo separa de la realidad exterior» (Paz, 1986: 36). Pero en el caso de Alejandra Pizarnik la palabra por ser puente termina encadenada en un hilo de las imágenes oníricas que conducen la unión del ser y de la palabra hacia el silencio absoluto. La búsqueda deja entonces de ser una mera herramienta, una introducción 
a un estado de vértigo en el cual la única fijación de la realidad del espacio poético son los emblemas poéticos (los símbolos que aparecen en la poética de Pizarnik, los más comunes son el espejo, la noche, la sed, el viento, el silencio, etc.), las imágenes que el personaje pizarnikiano crea como aquellos espacios en donde abandonarse después de la despersonalización. Y es precisamente esta búsqueda incesante de convertirse en el personaje pizarnikiano, poseído por el propio mundo textual, que conduce a la poeta hacia

[...] su autoinmolación. La letra se convirtió en fatum y el único camino trazado fue el suicidio. Las ideas perdieron entidad y eficacia, el silencio envolvió la página y los nombres se desmembraron, los sonidos cayeron y el cuaderno se transformó en tumba de un cadáver textual (Venti, 2008a: 48).

El acto del escribir entendido como fatum o el destino poético entonces supone un alejamiento de la imagen idealizada de Alejandra Pizarnik, esta «imagen absurda» que según Pizarnik comprendía a ella misma como una mujer «transformada en una distinguida poeta, galardonada y considerada como representativa de la poesía argentina» (Pizarnik, 2013: 822).

Lejos de la concepción determinista que analiza la obra de Alejandra solamente a través del suicidio, pretendemos pensar en el cumplimiento de este destino como el último intento de encontrar la verdad poética y de construir una realidad que esté fuera de lo ordinario, para acercarse a la abolición de los contrarios con tal de que la poesía abriese el camino hacia el infinito, es decir, con tal de que el poema mismo llegase a ser el centro del abandono de quien escribe: «el centro / de un poema / es otro poema / el centro del centro / es la ausencia / en el centro de la ausencia / mi sombra es el centro / del centro del poema» (Pizarnik, 2013: 381).

\section{El experimento irrepetible de Alejandra Pizarnik}

En uno de sus poemas más emblemáticos Sala de psicopatología Alejandra escribe: «[...] Para reunirme con el migo de conmigo y ser una sola y misma entidad con él tengo que matar al migo para que así se muera el con y, de / este modo, anulados los contrarios, la dialéctica supliciante finaliza en / la fusión de los contrarios» (Pizarnik, 2013: 414). La «dialéctica supliciante» es el término que mejor sintetiza la dinámica del ejercicio artístico de Alejandra Pizarnik. Al principio mencionamos este tipo de dialéctica explicando la relación de los contrarios, vinculando el ejercicio poético con los conceptos de 
fuga y búsqueda. Es precisamente esta noción de los contrarios que en la obra de Pizarnik posibilita diferentes lecturas de su poética, puesto que demuestra

la presencia de una realidad incompleta a la que se opone su imagen mediante la intervención de un elemento motor que condensa lo real y lo virtual en una unidad superior. Tanto si se trata de la intervencion del espejo y su movimiento, del impulso que se da al tirar la peonza o del reflejo expresivo del organismo, siempre advertimos una misma ley, que se resume en esta antigua formulación: LA OPOSICIÓN ES NECESARIA / PARA QUE LAS COSAS EXISTAN / Y SE FORME UNA / TERCERA REALIDAD (Bellmer, 2010: 25).

La oposición que nombra Alejandra es la oposición entre la vida y la poesía, el cuerpo y la palabra. El personaje pizarnikiano escribe debido a y a partir de la imposibilidad de la unión de estos opuestos, y para que el yo poético pueda sobrellevar la poesía como un modo de vivir o un modelo para nombrar («El terror es nombrado con el modelo delante, a fin de no equivocarse.» (Pizarnik, 2013: 289)) lo que no existe, es necesario «enlazar el texto con lo inverbalizable. [...] La intensa depuración de la palabra despliega sobre la blancura de la página buellas, marcas, cicatrices o grietas que denuncian, en la acción del canto, una semblanza de desvarío y destrucción» (Venti, 2008a: 214). Por ello, el acto del escribir tiene que asumirlo todo, - se nos presenta como una experiencia definitiva: el sujeto y el personaje pizarnikiano están sometidos a los cambios que surgen de la relación entre la vida y la poesía. Es la transformación de esta relación que forma la poética y el destino de Alejandra Pizarnik. Finalmente el destierro del lenguaje que era su única patria hace que esta transformación se convierta en un camino de dirección única, - en un experimento irrepetible. Por ello, como lectores, asistimos en la lectura de su obra a un llamamiento hacia lo ausente, hacia lo Otro, lo deseado. Idealizar el destino poético de Alejandra Pizarnik significaría entonces disminuir la realidad de la experiencia de lo poético como algo transformativo y subversivo y reduciría el destino trágico de la poeta solamente a uno de los estados temporales de su ser.

\section{La poesía como una experiencia post mortem}

La relación de Alejandra con la muerte, uno de los principales temas de su obra, es ambigua: por un lado entiende la muerte como una fantasía distante, anhelada, y por otro como un destino imposible. De tal modo, la muerte 
aparece siempre relacionada con dos instancias claves de la poética pizarnikiana: la vida y la poesía. La primera comprende la relación entre la vida y la muerte, que convencionalmente están en lados opuestos, pero Alejandra Pizarnik a propósito borra el límite que las separa. En el poema Balada de la piedra que llora: «la muerte se muere de risa pero la vida / se muere de llanto pero la muerte pero la vida / pero nada nada nada» (Pizarnik, 2013: 62) contrarresta la muerte y la vida para demostrar el imposible desenlace de ambas: «pero nada nada nada» (Pizarnik, 2013: 62). La dialéctica entre ambas instancias llega al punto culminante con el problema de la despersonalización, puesto que en el momento de la fragmentación del sujeto en las voces y de su esfuerzo por seguir escribiendo, no se borra solamente el límite entre la vida y la muerte, sino también el límite entre la vida y la poesía. En este espacio poético, encabezado por la ausencia y la fragmentación surge la idea del suicidio. Éste no aparece como una solución final del sujeto desdoblado, no significa la ejecución de su destino, de hacer su cuerpo con el del poema, sino todo lo contrario: suicidarse implica un alivio de las instancias (el lenguaje, la vida, el cuerpo, etc.) que dejaban a la poeta en continua desesperación. Alejandra escribe: «Suicidarse es poseer aquella máxima lucidez que permite reconocer que lo peor está ocurriendo ahora, aquí» (Pizarnik, 2013: 1090). ¿Cómo entonces tratar de resolver este conflicto interior para llegar hasta tal lucidez? Alejandra lo consigue mediante el uso del humor, la ironía; en un lenguaje paralizado por la fragmentación, encuentra una manera de sobrepasar los límites que existen entre la vida, la poesía y la muerte. Esta solución se encuentra en escribir, hablar de sí misma como si estuviera muerta. En los versos: «Delicia de perderse en la imagen presentida. Yo me levanté de mi cadáver, / yo fui en busca de quien soy. Peregrina de mí, he ido hacia la que duerme en un / país al viento.» (Pizarnik, 2013: 243) está reconociendo que la experiencia de la poesía es una experiencia post mortem, ya que solamente a través del acto subversivo, violento del escribir como si estuviera escribiendo desde su propio «cadáver», el poema como lo único verdadero y real puede establecerse como «[...] una reanimación textual del yo ausente» (Venti, 2008a: 211). Por tanto el ejercicio poético tal y como lo entiende Pizarnik no es solamente una experiencia de la destrucción (como pudimos observar anteriormente en el ejemplo de la corporeidad), sino también una experiencia post mortem, una búsqueda incesante de la transgresión, de la metamorfosis y de la invención de un sujeto que sostiene el cuerpo del poema a su muerte, a la pérdida del centro y finalmente, a la del sentido. 


\section{Conclusión}

A lo largo de este artículo hemos abordado, en primer lugar, la relación entre el cuerpo y la palabra desde el punto de vista del proceso de la despersonalización, viendo sus consecuencias (el sujeto en disolución, la fragmentación en varias voces, la enajenación de la corporeidad) a la luz del acto creativo como una transformación continua. Particularmente, nos hemos fijado en la triple negación que tiene lugar a nivel de la despersonalización: identitaria, la de corporeidad y la del valor ontologizador del lenguaje poético, subrayando la obsesión de la poeta con el lenguaje, la muerte o cualquier instancia que le permite transformar su vida a través del acto creativo en algo que sea creedero, real.

En segundo lugar, hemos examinado al personaje pizarnikiano con respecto a la imagen de Alejandra Pizarnik, la «poeta maldita» de la literatura argentina. Alejándose de la idealización de tal imagen, hemos optado por un análisis de la pérdida de la identidad y del rechazo del cuerpo, convertido en un punto fugitivo que impide al sujeto cualquier morada estable.

En tercer lugar, y a partir de las mencionadas propuestas de la lectura, hemos querido proponer una nueva mirada a la relación de los contrarios, contrarrestando los términos claves de la obra de Pizarnik como aquellas intancias en las que se origina la tensión principal del conflicto ontológico pizarnikiano. La muerte, la vida, la poesía, el suicidio y el lenguaje son los pilares de la obra de la autora argentina y son, al mismo tiempo su presidio, su liberación.

Leer la poesía de la poeta argentina como un experimento irrepetible y a la vez como una experiencia post mortem, significa intentar sobrepasar los límites de lo simbólico, puesto que, en el fondo de todas las preguntas y las contradicciones que plantea su obra, está la noción de la sutileza, de la lucidez que pone en evidencia el poder «encantatorio, exaltante, revolucionario, consolador» (Pizarnik, 2013: 300) de la poesía.

\section{Bibliografía}

Bellmer, H. (2010): Anatomía de la imagen. Barcelona: Ediciones de La Central. Cancellieri, N. (2011): «Fragmentación y descorporización del yo en la poesía de Alejandra Pizarnik». Tintas. Quaderni di letterature iberiche e iberoamericane, 1, 211-229: http://riviste.unimi.it/index.php/tintas (o8-08-2017). 
Daza, P. (2005): «Alejandra Pizarnik: "No puedo bablar con mi voz sino con mis voces”. Los perturbados entre las lilas.» Acta literaria, 30, 151-168: https:// dx.doi.org/10.4067/So717-68482005000100012 (08-08-2017).

Juliet, C. (1986): Giacometti. Milano: Jaca Book.

Lastra, P. (1985): «Notas sobre la poesia bispanoamericana actual.» Revista Chilena de Literatura, 25: http://www.revistaliteratura.uchile.cl/index.php/RCL/ article/download/41163/42700 (09-08-2017).

Paz, Octavio (1986): El arco y la lira : el poema : la revelación poética : poesía e bistoria. México: Fondo de Cultura Económica.

Piña, C. (1991): Alejandra Pizarnik. Buenos Aires: Grupo Editorial Planeta.

Pizarnik, A. (2012): Prosa completa (ed. Ana Becciú). Barcelona: Lumen.

Pizarnik, A. (2013): Diarios. Alejandra Pizarnik (ed. Ana Becciú). Barcelona: Lumen.

Pizarnik, A. (2013): Poesía completa (ed. Ana Becciú). Barcelona: Lumen.

Pizarnik, A. (2014): Nueva correspondencia Pizarnik (ed. Ivonne Bordelois, Cristina Piña). Ciudad Autónoma de Buenos Aires: Aguilar, Altea, Taurus, Alfaguara.

Sala Calafell, N. (2013): «Cuerpo / Pensamiento, ¿binomio imposible? La respuesta de Alejandra Pizarnik a las ideas teatrales de Antonin Artaud». Alicante: Biblioteca Virtual Miguel de Cervantes: http://www.cervantesvirtual. com/nd/ark:/59851/bmct7467 (07-08-2017).

Venti, P. (2008a): La escritura invisible. El discurso autobiográfico en Alejandra Pizarnik. Barcelona: Anthropos Editorial.

Venti, P. (2008b) La dama de estas ruinas. Un estudio sobre La Condesa Sangrienta de Alejandra Pizarnik. El Escorial: Editorial Dedalus. 
Nada Kavčič

Ljubljana

\section{A poetical itinerary of a body in vertigo: the persona of Alejandra Pizarnik and the ontological function of depersonalization of the poetical self}

Keywords: Alejandra Pizarnik, corporality, the ontological function of the poetical language, depersonalization, unrepeatable experiment

In this article we take as our starting point the bond between the corporeal and the word and use this to analyse the process of depersonalization and the creation of the poetical persona in the works of Alejandra Pizarnik. We seek to define the disappearance of the subject engendered by the writing process itself with reference to individual poems by Pizarnik. As a result of the continual disappearance of the subject and of the inadequacy of language, the act of writing can be understood as an unrepeatable experiment as well as a reflection of a failed attempt by the poet to merge the corporeal and the word as well as life and poetry as a post-death experience, since the subject alienates its own corporeality by writing as if deceased. This conceit has the effect of enabling poem to be seen as an eternal invocation of the absent. 
Nada Kavčič

Ljubljana

\section{Pesniški itinerarij telesa v vrtoglavici: persona Alejandre Pizarnik in ontološka funkcija depersonalizacije pesniškega jaza}

Ključne besede: Alejandra Pizarnik, telesnost, ontološka funkcija pesniškega jezika, depersonalizacija, neponovljivi eksperiment

V članku je predstavljena vez med telesom in besedo, na podlagi katere so analizirani tudi postopki depersonalizacije ter kreacije pesniške persone $\mathrm{v}$ delih Alejandre Pizarnik. Preko navezav na posamezne pesmi članek poskuša opredeliti ponikanja subjekta, ki se vzpostavlja v procesu pisanja. Zaradi nenehnih ponikanj subjekta ter nezadostnosti jezika je akt pisanja razumljen hkrati kot neponovljivi eksperiment, odraz neuspelega poskusa, da bi pesnica združila telo in besedo, življenje in poezijo, ter kot izkušnja post mortem, saj subjekt preko potujitve telesnosti piše kot že mrtev zato, da se pesem lahko vzpostavi kot nenehno priklicevanje odsotnega. 